\title{
Attitudes Towards and Perceptions Regarding the Implementation of Evidence-Based Practice Among Omani Nurses
}

$$
\begin{gathered}
\text { الاتحاهات نحو و التصورات لتنفيذ الممارسات القائمة على الأدلة بين الممرضات العمانيات } \\
\text { المحات }
\end{gathered}
$$

$$
\text { محمد عامر المسكري و باربرة باترسون }
$$

ABSTRACT: Objectives: This study aimed to explore the attitudes of Omani nurses towards evidence-based practice (EBP) and their perceptions of the barriers to and facilitators of EBP implementation in Oman. In addition, the attitudes and perceptions of nurse leaders and staff nurses were compared. Methods: This descriptive cross-sectional study was conducted between August and October 2016 in three suburban governmental hospitals in Northern Oman. A demographic questionnaire and two EBP instruments were used to collect data from 282 registered Omani nurses, including the Evidence-Based Nursing Attitude Questionnaire and the Developing Evidence-Based Practice Questionnaire. Results: A total of 260 Omani nurses took part in the study (response rate: $92.2 \%$ ). On the whole, the nurses had positive attitudes towards EBP, with no significant difference in mean attitude scores per item between staff nurses and nurse leaders ( $3.98 \pm 0.46$ versus $4.03 \pm 0.50 ; P=0.431$ ). However, in comparison to staff nurses, nurse leaders had higher scores per item for the barriers to changing practice and finding and reviewing evidence subsections, with lower scores for the facilitators to changing practice section. Conclusion: In accordance with the international literature, Omani nurses had positive attitudes towards EBP as well as similar perceptions of barriers and facilitators to EBP implementation. These findings may help to inform recommendations for the integration of EBP in educational programmes and clinical settings in Oman, as well as to facilitate necessary changes in nursing practice.

Keywords: Evidence-Based Practice; Nurses; Attitudes; Perceptions; Oman.

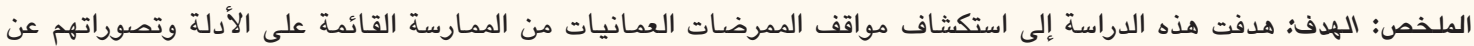

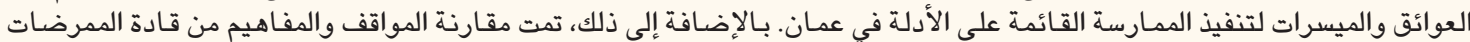

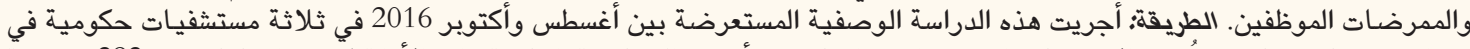

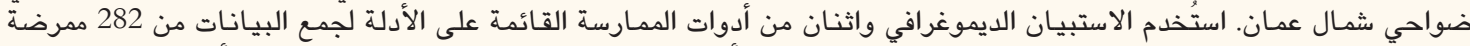

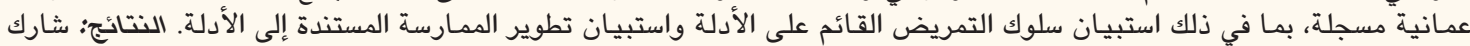

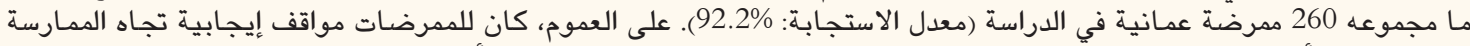

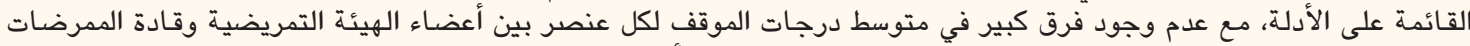

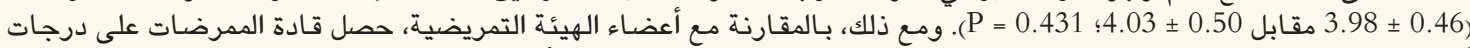

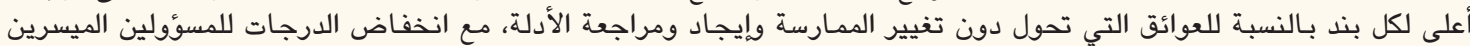

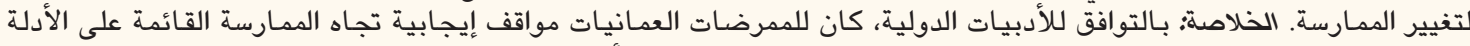

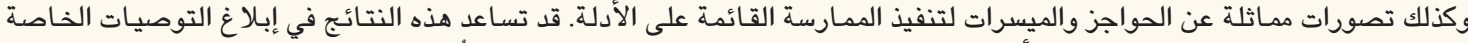

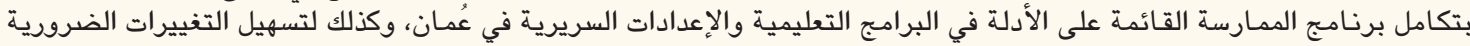
في ممارسة التمريض.

$$
\text { الكلمات المفتاحية: الممارسة القائمة على الأدلة؛ الممرضات؛ الاتجاهـات؛ التصورات؛ عمان. }
$$

\section{AdVANCES IN KNOWLEDGE}

This study demonstrates that there is a need to explore factors that may act as barriers to or facilitators for the implementation of evidence-based practice (EBP) in Oman.

Recommendations are suggested to facilitate the adoption of EBP and improve the quality of nursing practice in Oman.

\section{Application to Patient Care}

The integration of EBP in nursing education and clinical practice may improve the quality of nursing care provided to patients and, ultimately, positively influence patient outcomes. 
$\mathrm{E}$ VIDENCE-BASED PRACTICE (EBP) IS A PROBLEMsolving approach to the delivery of healthcare that seeks to integrate the best available evidence from existing research with clinician expertise and patient preferences. ${ }^{1,2}$ In this way, patients can receive the highest quality of care and achieve the best outcomes. For nurses, EBP is considered an effective way of enhancing confidence in clinical decision-making. ${ }^{2-4}$ Additionally, EBP can enhance clinical judgment, keep nurses' knowledge up-to-date and increase the accountability of healthcare workers. ${ }^{5-8}$ Nevertheless, despite the significant benefits of EBP, many factors may act as barriers to the implementation of EBP, with some researchers arguing that the global application of EBP continues to advance slowly for these reasons. ${ }^{9}$

As in other Middle Eastern countries, nurses in Oman face many challenges when implementing EBP, including a lack of time and resources, high workload volume and the lack of authority to make changes in current practice. ${ }^{10,11}$ The Ministry of Health $(\mathrm{MOH})$ in Oman has recognised the significance of implementing EBP in clinical settings and has provided multiple workshops and in-service training programmes for nurses; however, many nurses still lack essential knowledge and skills for EBP implementation. ${ }^{11}$ To the best of the authors' knowledge, only one previous study has documented the attitudes of nurses working in Oman towards the implementation of EBP. ${ }^{11}$ This study therefore aimed to explore the attitudes of Omani nurses towards the implementation of EBP and their perceptions of barriers to and facilitators of EBP implementation. In addition, this study aimed to compare differences in the attitudes and perceptions of Omani nurse leaders and staff nurses as these individuals hold key roles in the provision of high-quality nursing care.

\section{Methods}

This descriptive cross-sectional study was conducted between August and October 2016. A convenience sample was recruited of Omani nurses working in three suburban governmental hospitals in Northern Oman. All registered full-time nurses with two or more years' experience and who could speak, read and write English fluently were included in the study. However, nurses with less than two years of experience and who were not Omani nationals were excluded. Subjects were classified as nurse leaders based on their role, at least six months of leadership experience and job title (i.e. nurse-in-charge, nurse manager or head of a unit). The nurses were recruited from all hospital units, including medical/surgical units, paediatric/maternity units, critical care, administration, staff development and infection control departments and outpatient clinics. A power analysis, based on a medium effect size of 0.50 , a twotailed $P$ value of $\leq 0.050$, and a power of 0.80 , was conducted; according to this calculation, the required sample size was 128 participants.

A demographic questionnaire and two EBP tools were used for data collection. All instruments were administered in English. The demographic questionnaire consisted of 11 items including age, gender, job title, level of education, years of nursing leadership experience, work setting and their prior experience of EBP in nursing education, continuing education and in the workplace. Subsequently, the Evidence-Based Nursing Attitude Questionnaire (EBNAQ) was used to measure nurses' attitude towards EBP in light of its clear and concise language and relevance to nursing practice. ${ }^{12}$ This tool consists of 15 items grouped into three dimensions (cognitive, affective and behavioural). Responses were scored on a five-point Likert scale, ranging from one for 'strongly disagree' to five for 'strongly agree.12 Finally, the Developing Evidence-Based Practice (DEBP) questionnaire was used to measure barriers and facilitators of EBP. ${ }^{13}$ The DEBP tool consists of 49 items categorised into five sections: (1) bases of practice knowledge; (2) barriers to finding and reviewing evidence; (3) barriers to changing practice on the basis of evidence; (4) facilitation and support in changing practice; and (5) skills in finding and reviewing evidence. Responses were scored on a five-point Likert scale, with items scored differently in each section. For the first section, one indicated 'never' and five 'always', while one denoted 'strongly agree' and five 'strongly disagree' in sections two, three and four and one was 'complete beginner' and five 'expert' in the final section. ${ }^{13}$ For the purposes of this study, Cronbach's alpha values indicated good reliability for various subsections of the EBNAQ and DEBP [Table 1].

Introductory sessions to introduce nurses to the study were conducted at each hospital; these sessions were also used as a tool to answer any questions from potential subjects. In addition, flyers were distributed to all hospital units. Both the introductory sessions and the flyers included information regarding the study, such as the inclusion and exclusion criteria, directions on how to complete the questionnaires, the distribution and collection procedures of the questionnaires and the contact information of the researchers. After the flyers were distributed, subjects were approached and invited to participate in the study. A total of 282 questionnaires were distributed.

The Statistical Package for the Social Sciences (SPSS), Version 24.0 (IBM Corp., Armonk, New York, USA), was used for data analysis. Descriptive and inferential 
Table 1: Reliability of the Evidence-Based Nursing Attitude Questionnaire ${ }^{12}$ and Developing Evidence-based Practice Questionnaire ${ }^{13}$ among Omani staff nurses and nurse leaders at three hospitals in Northern Oman $(\mathrm{N}=260)$

\begin{tabular}{|c|c|c|}
\hline \multirow{2}{*}{$\begin{array}{l}\text { Instrument } \\
\text { subsection }\end{array}$} & \multicolumn{2}{|c|}{ Cronbach's alpha coefficient } \\
\hline & $\begin{array}{l}\text { Nurse leaders } \\
\quad(\mathbf{n}=98)\end{array}$ & $\begin{array}{l}\text { Staff nurses } \\
(\mathrm{n}=162)\end{array}$ \\
\hline EBNAQ & 0.84 & 0.82 \\
\hline $\begin{array}{l}\text { Beliefs and expectations } \\
\text { towards EBP }\end{array}$ & 0.72 & 0.81 \\
\hline $\begin{array}{l}\text { Intention of conduct } \\
\text { towards EBP }\end{array}$ & 0.51 & 0.45 \\
\hline Feelings towards EBP & 0.78 & 0.62 \\
\hline \multicolumn{3}{|l|}{ DEBP } \\
\hline Knowledge of EBP & 0.83 & 0.89 \\
\hline $\begin{array}{l}\text { Barriers to finding and } \\
\text { reviewing evidence }\end{array}$ & 0.79 & 0.81 \\
\hline $\begin{array}{l}\text { Barriers to changing } \\
\text { practice }\end{array}$ & 0.65 & 0.72 \\
\hline $\begin{array}{l}\text { Facilitators to changing } \\
\text { practice }\end{array}$ & 0.81 & 0.82 \\
\hline $\begin{array}{l}\text { Skills in finding and } \\
\text { reviewing evidence }\end{array}$ & 0.86 & 0.91 \\
\hline
\end{tabular}

EBNAQ = Evidence-Based Nursing Attitude Questionnaire; EBP = evidence-based practice; DEBP = Developing Evidence-based Practice Questionnaire.

statistics were used to analyse the findings. An independent $t$-test was used to compare differences in the mean attitude scores of nurse leaders and staff nurses, as well as differences in barriers to finding and reviewing evidence (e.g. insufficient resources, insufficient time at work and lack of authority to implement change in practice), barriers to changing practice (e.g. insufficient time to find research reports, lack of confidence and difficulty understanding research reports) and facilitators to changing practice (e.g. support from nursing colleagues, nurse managers and doctors). Additional analyses using Pearson's correlation coefficient were conducted to determine correlations with age, gender, years of nursing experience and EBP variables. A $P$ value of $\leq 0.050$ was deemed statistically significant.

This study received ethical approval from the Institutional Review Board of the MOH (\#MH/DGP/ $R \& S / 21 / 2016)$. All data were anonymised and kept confidential and participation was voluntary in nature. In addition, information about the aims and procedures of the study, the estimated time to complete the questionnaire and the rights of the participants was provided to all subjects.
Table 2: Demographic characteristics of Omani staff nurses and nurse leaders at three hospitals in Northern Oman $(\mathrm{N}=260)$

\begin{tabular}{|c|c|c|c|}
\hline \multirow[t]{2}{*}{ Characteristic } & \multicolumn{3}{|c|}{ n (\%) } \\
\hline & Total & $\begin{array}{l}\text { Nurse } \\
\text { leaders } \\
(\mathbf{n}=98)\end{array}$ & $\begin{array}{c}\text { Staff nurses } \\
(\mathrm{n}=162)\end{array}$ \\
\hline \multicolumn{4}{|l|}{ Gender } \\
\hline Male & $45(17.3)$ & 21 (21.4) & $24(14.8)$ \\
\hline Female & $215(82.7)$ & 77 (78.6) & $138(85.2)$ \\
\hline \multicolumn{4}{|l|}{ Age in years } \\
\hline Mean \pm SD & $32.7 \pm 4.7$ & $35.0 \pm 5.0$ & $30.4 \pm 4.5$ \\
\hline Range & $24-50$ & $24-50$ & $24-43$ \\
\hline \multicolumn{4}{|l|}{ Job title } \\
\hline $\begin{array}{l}\text { Nurse in- } \\
\text { charge }\end{array}$ & $74(28.5)$ & $74 .(75.5)$ & $0(0)$ \\
\hline $\begin{array}{l}\text { Nurse } \\
\text { supervisor }\end{array}$ & $3(1.2)$ & $3(3.1)$ & $0(0)$ \\
\hline Unit nurse & $17(6.5)$ & $17(17.3)$ & $0(0)$ \\
\hline $\begin{array}{l}\text { Head of } \\
\text { nursing }\end{array}$ & $4(1.5)$ & $4(4.1)$ & $0(0)$ \\
\hline Staff nurse & $162(62.3)$ & $0(0)$ & $162(100)$ \\
\hline \multicolumn{4}{|l|}{ Education level } \\
\hline Diploma & $159(61.2)$ & $51(52)$ & $108(66.7)$ \\
\hline $\begin{array}{l}\text { Specialised } \\
\text { diploma }\end{array}$ & $58(22.3)$ & 33 (33.7) & 25 (15.4) \\
\hline $\begin{array}{l}\text { Bachelor's } \\
\text { degree }\end{array}$ & $42(16.2)$ & $14(14.3)$ & $28(17.3)$ \\
\hline Master's degree & $1(0.4)$ & $0(0)$ & $1(0.6)$ \\
\hline \multicolumn{4}{|c|}{ Prior exposure to EBP in nursing education } \\
\hline No & $17(6.5)$ & $6(6.1)$ & $11(6.8)$ \\
\hline Yes & 184. (70.8) & $67(68.4)$ & $117(72.2)$ \\
\hline Unsure & $59(22.7)$ & $25(25.5)$ & $34(21)$ \\
\hline
\end{tabular}

Prior exposure to EBP at CNE activities*

$\begin{array}{llll}\text { No } & 114(43.8) & 30(30.6) & 84(51.9) \\ \text { Yes } & 146(56.2) & 68(69.4) & 78(48.1)\end{array}$

Prior implementation of EBP at work

$\begin{array}{lccc}\text { No } & 34(13.1) & 9(9.2) & 25(15.4) \\ \text { Sometimes } & 181(69.6) & 75(76.5) & 106(65.4) \\ \text { Always } & 18(6.9) & 9(9.2) & 9(5.6) \\ \text { Unsure } & 27(10.4) & 5(5.1) & 22(13.6)\end{array}$

$S D=$ standard deviation $; E B P=$ evidence-based practice $; C N E=$ continuous nursing education.

*Previous attendance at EBP-related conferences, workshops or seminars. 
Table 3: Mean total scores and scores per item for attitudes towards evidence-based practice* and perceived barriers and facilitators ${ }^{\dagger}$ among Omani staff nurses and nurse leaders at three hospitals in Northern Oman $(\mathrm{N}=260)$

\begin{tabular}{lccccc}
\hline Questionnaire section & \multicolumn{2}{c}{ Mean total score \pm SD } & \multicolumn{2}{c}{ Mean score per item \pm SD } & $P$ value \\
& $\begin{array}{c}\text { Nurse leaders } \\
(\mathbf{n}=\mathbf{9 8})\end{array}$ & $\begin{array}{c}\text { Staff nurses } \\
(\mathbf{n}=\mathbf{1 6 2})\end{array}$ & $\begin{array}{c}\text { Nurse leaders } \\
(\mathbf{n}=\mathbf{9 8})\end{array}$ & $\begin{array}{c}\text { Staff nurses } \\
(\mathbf{n}=\mathbf{1 6 2})\end{array}$ \\
& $60.40 \pm 7.48$ & $59.68 \pm 6.91$ & $4.03 \pm 0.50$ & $3.98 \pm 0.46$ & 0.431 \\
Attitudes towards EBP & $28.59 \pm 5.59$ & $26.85 \pm 5.52$ & $2.57 \pm 0.62$ & $2.45 \pm 0.71$ & 0.176 \\
Barriers to changing practice & $12.84 \pm 3.11$ & $12.27 \pm 3.57$ & $2.86 \pm 0.56$ & $2.68 \pm 0.55$ & 0.015 \\
Barriers to finding and reviewing evidence & $10.41 \pm 3.22$ & $11.12 \pm 3.38$ & $2.60 \pm 0.80$ & $2.78 \pm 0.84$ & 0.096
\end{tabular}

$S D=$ standard deviation EBP $=$ evidence-based practice.

*Self-assessed using the English-language 15-item Evidence-Based Nursing Attitude Questionnaire. ${ }^{12}{ }^{\dagger}$ Self-assessed using the English-language 49-item Developing Evidence-Based Practice (DEBP) questionnaire. ${ }^{13}$

\section{Results}

A total of 282 questionnaires were distributed, of which 269 were completed; however, nine questionnaires were excluded due to missing data. Therefore, a total of 260 nurses were included in the analysis (response rate: 92.2\%). Of these, 162 (62\%) were staff nurses and 98 (38\%) were nurse leaders. The majority of the nurses were female (82.7\%). Most had a diploma in nursing (61.2\%), with $22.3 \%$ holding a specialised degree in nursing and $16.2 \%$ a Bachelor's degree in nursing. Only one nurse had a Master's degree in nursing (0.4\%). Although 70.8\% of the subjects had learned about EBP during their nursing education, $6.5 \%$ had not and $22.7 \%$ could not remember. A total of 145 nurses (56.2\%) had previously attended EBP-related conferences, workshops or seminars and 69.6\% reported occasional implementation of EBP at their workplace [Table 2].

Overall, the Omani nurses had positive attitudes towards EBP. There were no significant differences in mean score per item in the attitudes subsection between staff nurses and nurse leaders $(P=0.431)$. This was also the case for the barriers to changing practice and facilitators to changing practice subsections $(P=0.176$ and 0.096, respectively). However, there was a significant difference in the mean score per item for the barriers to finding and reviewing evidence subsection $(P=0.015)$ [Table 3].

There was no significant relationship between age, gender, years of nursing experience and EBP variables for either group. However, the groups differed significantly in terms of education level and their mean score per item in the attitude subsection $(P<0.001)$ [Table 4$]$. Moreover, nurses who had had prior exposure to EBP in nursing education and via CNE sessions differed significantly in their overall attitudes towards EBP compared to those without prior exposure $(P=0.004$ and 0.014 , respectively). Furthermore, there was a significant diff-
Table 4: Association between education level and mean score per item for attitudes towards evidence-based practice $^{*}$ and perceived barriers and facilitators ${ }^{\dagger}$ among Omani staff nurses and nurse leaders at three hospitals in Northern Oman $(\mathrm{N}=259)^{\ddagger}$

\begin{tabular}{|c|c|c|}
\hline Questionnaire section & $\begin{array}{c}\text { Mean } \\
\text { score per } \\
\text { item } \pm \text { SD }\end{array}$ & $P$ value ${ }^{\S}$ \\
\hline \multicolumn{3}{|l|}{ Attitudes towards EBP } \\
\hline Diploma holders & $3.88 \pm 0.47$ & \multirow{3}{*}{$<0.001$} \\
\hline Specialised diploma holders & $4.16 \pm 0.44$ & \\
\hline Bachelor's degree holders & $4.20 \pm 0.41$ & \\
\hline \multicolumn{3}{|c|}{ Barriers to finding and reviewing evidence } \\
\hline Diploma holders & $2.70 \pm 0.53$ & \multirow{3}{*}{0.092} \\
\hline Specialised diploma holders & $2.79 \pm 0.61$ & \\
\hline Bachelor's degree holders & $2.90 \pm 0.60$ & \\
\hline \multicolumn{3}{|c|}{ Barriers to changing clinical practice } \\
\hline Diploma holders & $2.47 \pm 0.68$ & \multirow{3}{*}{0.331} \\
\hline Specialised diploma holders & $2.61 \pm 0.68$ & \\
\hline Bachelor's degree holders & $2.43 \pm 0.66$ & \\
\hline \multicolumn{3}{|c|}{ Facilitators to changing practice } \\
\hline Diploma holders & $2.65 \pm 0.81$ & \multirow{3}{*}{0.198} \\
\hline Specialised diploma holders & $2.78 \pm 0.95$ & \\
\hline Bachelor's degree holders & $2.89 \pm 0.68$ & \\
\hline \multicolumn{3}{|c|}{$S D=$ standard deviation $; E B P=$ evidence-based practice } \\
\hline \multicolumn{3}{|c|}{ 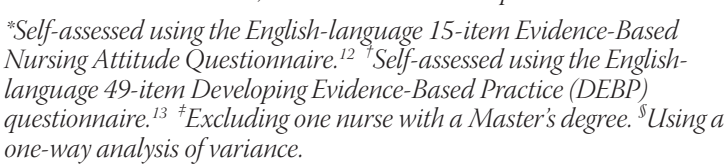 } \\
\hline
\end{tabular}

erence in the barriers to finding and reviewing evidence $(P=0.015)$, barriers to changing practice $(P<0.001)$ and facilitators of EBP $(P=0.007)$ scores between nurses who did and those who did not report prior EBP implementation at their workplace. 


\section{Discussion}

To the best of the authors' knowledge, this is the second study to examine attitudes of Omani nurses towards EBP and perceived barriers to EBP implementation. ${ }^{11}$ The present study had a high response rate, which may be due to three possible explanations. First, the Omani culture incorporates a strong sense of community in which helpfulness is highly valued. Second, there is a possibility that the nurses felt proud to be part of a research project and to play a role in advancing the nursing profession in Oman. Third, there may have been a perceived sense of obligation to participate despite the anonymous approach to data collection. Nevertheless, the findings of this study add to the existing body of knowledge related to EBP implementation in Oman and the importance of establishing appropriate nursing strategies in a clinical setting. This information could be of use in other countries which share similar cultures and nursing practices. Additionally, the results of this study provide directions for future research aimed at optimising the implementation of EBP in Oman, for example by integrating EBP modules into the pre-licensure nursing curricula.

Overall, the findings of the current study indicated that the Omani nurses held positive attitudes towards EBP. These findings are consistent with those of other studies conducted in both Western and Eastern countries. ${ }^{1,9,14-16}$ Positive attitudes towards EBP are a good foundation for appropriate nursing strategies to be developed to promote its implementation in Oman. However, the effect of frequent exposure to EBP workshops and training programmes and/or the Hawthorne observer effect might have played a major role in influencing nurses' attitudes towards EBP and increasing awareness of its significance in clinical settings. ${ }^{1,5}$ In recent years, the Omani $\mathrm{MOH}$ has conducted multiple workshops and training programmes for nurses to improve EBP-related knowledge and skills and to be consistent with the standards of international healthrelated organisations such as the Quality and Safety Education for Nurses Institute. Such factors may have played a role in promoting positive attitudes towards EBP.

Nurses in the present study had higher scores in the barriers to finding and reviewing evidence subsection compared to the barriers to and facilitators of changing practice sections. These findings are consistent with those of other studies, which found that nurses perceived barriers to finding and reviewing evidence to be more problematic than those relating to changing practice, mainly due to a lack of EBP knowledge/skills, time and resources. ${ }^{11,13}$
Nurse leaders play an important role in EBP implementation by promoting a supportive environment as well as providing the necessary resources required for its successful application. Additionally, nurse leaders can create policies and guidelines that promote EBP implementation as well as collaborate with experts to provide additional EBP training workshops for staff nurses. In accordance with previous studies, there was no significant difference in mean attitude scores between staff nurses and nurse leaders. ${ }^{6,9,10,14,15}$ However, nurse leaders had higher scores in the barriers to changing practice subsection and lower scores in the facilitators to changing practice section compared to staff nurses. This may have been due to a lack of EBP-related knowledge and skills among nurse leaders. Alternatively, as nurse leaders are usually more experienced than staff nurses and may have a better understanding of the organisational context of their institution, they might simply recognise that they have limited resources for EBP implementation. ${ }^{1,9}$

In the current study, there was a significant difference between the two groups in terms of educational level and their EBP attitude scores, indicating that increased education levels had a positive effect on overall attitudes towards EBP. This is consistent with the results reported in other studies. ${ }^{1,10,11}$ This finding provides evidence for the importance of educational programmes for Omani nurses which focus on promoting EBP knowledge and skills. Furthermore, understanding differences in the perceptions of EBP barriers and facilitators between staff nurses and nurse leaders may lead to targeted programmes for each group.

The results of the current study should be interpreted in light of its limitations. A convenience sampling method was used to recruit participants from three hospitals in Northern Oman; as such, the findings may not be representative of nurses in other regions. Therefore, it would be useful to conduct further research with a larger and more representative sample. Also, as the instruments used in this study were disseminated in English, there was a potential risk that some subjects were not able to understand some of the items. However, the English-language EBNAQ and DEBP instruments have high validity and reliability; additionally, the participants underwent an English-language proficiency check as part of the inclusion and exclusion criteria. ${ }^{13,14}$ Additionally, most of the cohort were diploma holders and would not have been prepared for EBP during their diploma; therefore, such nurses may perceive greater barriers towards its implementation. Finally, since the responses to the questionnaires were based on self-reported data, the data may have been affected by response bias and/or the Hawthorne observer effect. 


\section{Conclusion}

Both Omani staff nurses and nurse leaders had positive attitudes towards EBP. The importance of nurse leaders in EBP implementation should not be underestimated, as such individuals may act as role models and play a key role in ensuring a supportive environment. The findings of this study may be useful in developing strategies to integrate EBP into the nursing curricula in Oman, ultimately improving patient care outcomes.

\section{CONFLICT OF INTEREST}

The authors declare no conflicts of interest.

\section{FUNDING}

No funding was received for this study.

\section{References}

1. Williamson KM, Almaskari M, Lester Z, Maguire D. Utilization of evidence-based practice knowledge, attitude, and skill of clinical nurses in the planning of professional development programming. J Nurses Prof Dev 2015; 31:73-80. doi: 10.1097/NND. 0000000000000140 .

2. Melnyk BM, Fineout-Overholt E, Gallagher-Ford L, Stillwell SB. Evidence-based practice, step by step: Sustaining evidence-based practice through organizational policies and an innovative model. Am J Nurs 2011; 111:57-60. doi: 10.1097/01.NAJ.0000405063. 97774.0e.

3. Al Hadid LA, Hasheesh MA, Al Momani M. Validating a tool that explores factors influencing the adoption of principles of evidence-based practice. J Nurs Educ 2011; 50:681-7. doi: 10.39 28/01484834-20110930-03

4. Malik G, McKenna L, Plummer V. Perceived knowledge, skills, attitude and contextual factors affecting evidence-based prac tice among nurse educators, clinical coaches and nurse specialists. Int J Nurs Pract 2015; 21:46-57. doi: 10.1111/ijn.12366.

5. Melnyk BM, Fineout-Overholt E. Evidence-Based Practice in Nursing \& Healthcare: A guide to best practice, 2nd ed. Philadelphia, Pennsylvania, USA: Lippincott Williams \& Wilkins, 2010. Pp. 3-39.
6. Facchiano L, Snyder CH. Evidence-based practice for the busy nurse practitioner: Part one: Relevance to clinical practice and clinical inquiry process. J Am Acad Nurs Pract 2012; 24:579-86. doi: 10.1111/j.1745-7599.2012.00748.x.

7. Upton D, Upton P, Scurlock-Evans L. The reach, transferability, and impact of the Evidence-Based Practice Questionnaire: A methodological and narrative literature review. Worldviews Evid Based Nurs 2014; 11:46-54. doi: 10.1111/wvn.12019.

8. Varaei S, Salsali M, Cheraghi MA. Implementation of evidencebased nursing practice for diabetic patients: An Iranian experience. Int J Nurs Pract 2013; 19:73-80. doi: 10.1111/ijn.12170.

9. Melnyk BM, Gallagher-Ford L, Long LE, Fineout-Overholt E. The establishment of evidence-based practice competencies for practicing registered nurses and advanced practice nurses in real-world clinical settings: Proficiencies to improve healthcare quality, reliability, patient outcomes, and costs. Worldviews Evid Based Nurs 2014; 11:5-15. doi: 10.1111/wvn.12021.

10. Adib-Hajbaghery M. Evidence-based practice: Iranian nurses' perceptions. Worldviews Evid Based Nurs 2009; 6:93-101. doi: 10.1111/j.1741-6787.2009.00149.x.

11. Ammouri AA, Raddaha AA, Dsouza P, Geethakrishnan R, Noronha JA, Obeidat AA, et al. Evidence-based practice: Knowledge, attitudes, practice and perceived barriers among nurses in Oman. Sultan Qaboos Univ Med J 2014; 14:e537-45.

12. Ruzafa-Martínez M, López-Iborra L, Madrigal-Torres M. Attitude towards evidence-based nursing questionnaire: Development and psychometric testing in Spanish community nurses. J Eval Clin Pract 2011; 17:664-70. doi: 10.1111/j.1365-2753.2011.01677x.

13. Gerrish K, Ashworth P, Lacey A, Bailey J. Developing evidencebased practice: Experiences of senior and junior clinical nurses. J Adv Nurs 2008; 62:62-73. doi: 10.1111/j.1365-2648.2007.04579.x.

14. Ez elarab HS, El Salam SA, Behalik SG, Eltayeb HE. Nurses' practice, knowledge and attitude towards evidence-based practice at Yanbu General Hospital, Kingdom of Saudi Arabia. Life Sci J 2012; 9:1062-71.

15. Gallagher-Ford L. The influence of nurse leaders and nurse educators on registered nurses' evidence-based practice. PhD. Thesis, 2012, Widener University, Chester, Pennsylvania, USA.

16. Linton MJ, Prasun MA. Evidence-based practice: Collaboration between education and nursing management. J Nurs Manag 2013; 21:5-16. doi: 10.1111/j.1365-2834.2012.01440.x. 